\title{
African Cuisine-Centered Insulin Therapy: Expert Opinion on the Management of Hyperglycaemia in Adult Patients with Type 2 Diabetes Mellitus
}

\author{
Jean Claude Mbanya (D) - Roberta Lamptey (D) - Andrew E. Uloko (D) \\ Amos Ankotche · Gontle Moleele · Gaman Ali Mohamed • \\ Iswaraj Ramracheya · Kaushik Ramaiya · Malusi Ndiweni • \\ Maïmouna Ndour Mbaye · Silver Bahendeka · Sanjay Kalra
}

Received: August 27, 2020 / Accepted: October 23, 2020 / Published online: November 9, 2020

(C) The Author(s) 2020

\section{ABSTRACT}

The prevalence of diabetes in sub-Saharan Africa (SSA) is growing rapidly, and a steadily increasing number of adults are estimated to be living with type 2 diabetes mellitus (T2DM). Insulin therapy is the treatment of choice in patients who present with severe hyperglycaemia and in most of those who do not achieve target goals

Jean Claude Mbanya and Roberta Lamptey contributed equally to this work.

J. C. Mbanya $(\bowtie)$

Laboratory of Molecular Medicine and Metabolism, Biotechnology Center, University of Yaoundé,

Yaoundé, Cameroon

e-mail: jcmbanya@yahoo.co.uk

\section{J. C. Mbanya}

Department of Internal Medicine and Specialties, Faculty of Medicine and Biomedical Sciences,

University of Yaoundé, Yaoundé, Cameroon

\section{R. Lamptey}

Department of Family Medicine, Korle Bu Teaching Hospital-University of Ghana, Accra, Ghana

\section{R. Lamptey}

Department of Community Health, University of

Ghana Medical School, Accra, Ghana

e-mail: roberta.lamptey@yahoo.com

\section{A. E. Uloko}

Department of Medicine, Bayero University Kano /

Aminu Kano Teaching Hospital, Kano, Nigeria

e-mail: andyuloko@yahoo.com on oral hypoglycaemic agents. Initiating treatment with the appropriate type of insulin based on the meal patterns and lifestyle of the individual patient is a strategy that is more likely than others to improve glycaemic control and adherence. African cuisine typically has a high carbohydrate load. Given these predominantly carbohydrate-rich food habits, it is essential to modify this dietary pattern whilst at the same time ensuring that insulin therapy is initiated, titrated and maintained in a timely manner, as needed to suit the patient's habits. To date, there are no published clinical guidelines to

\section{A. Ankotche}

Department of Internal Medicine, Enocrinology and Geriatrics, Unit of Training and Research, Medical Science of Abidjan, University of Côte D'Ivoire, Abidjan, Ivory Coast

\section{G. Moleele}

Department of Endocrinology, Bokamoso Private Hospital, Mmopane, Botswana

G. A. Mohamed

Comprehensive Diabetes Centre, Nairobi, Kenya

I. Ramracheya

Heart and Wellness Centre, Wellkin Hospital, Moka, Mauritius

K. Ramaiya

Shree Hindu Mandal Hospital, Chusi Street, Dar es Salaam, Tanzania

M. Ndiweni

Diabetes and Endocrine Centre, Harare, Zimbabwe 
guide practitioners and patients on tailoring insulin to match the high carbohydrate content in African cuisine. To address this gap, we have reviewed current insulin therapy practices and propose a patient-centric guide to insulin therapy based on African cuisine. A literature search was conducted for studies published in English up to November 2019 that focused on the choice of insulin and its dosing in relation to African foods. All articles extracted were reviewed by an expert group. The recommendation of the expert group was that basal-bolus and premix insulin regimens are best suited to manage post-meal glycaemia in African cuisine. The timing and constituents of the meal, portion sizes, glycaemic load and glycaemic index of meals should be considered when choosing the type of insulin and insulin regimen. Assessment of individual preferences and comorbidities should be prioritised and form an integral part of diabetes management.

Keywords: African cuisine; Carbohydrate; Insulin therapy; Meal pattern; Type 2 diabetes

\section{Key Summary Points}

The insulin dosage/treatment regimen should be individualised based on individual patient factors. Meal pattern and regular self-blood glucose measurements are key considerations to the individualisation of insulin therapy.

M. N. Mbaye

Centre du Diabète Marc Sankalé, Dakar, Senegal

S. Bahendeka

Department of Internal Medicine, Mother Kevin

Postgraduate Medical School, Uganda Martyrs

University, Kampala, Uganda

S. Kalra

Department of Endocrinology, Bharti Hospital, Karnal, India
African cuisine, although difficult to describe, predominantly comprises starchy carbohydrates, vegetables and plant sources of fats. The carbohydrate composition for an 'ethnic cuisine' varies widely depending on whether the ethnic group is rural, urban or migrant. Meal patterns in sub-Saharan Africa range from one to three meals per day and should be taken into account in the management of patients with type 2 diabetes mellitus (T2DM).

To attain good post-meal glycaemia, it is necessary to estimate the carbohydrate amount in the meal and use the calculated load to estimate the insulin dose. Patients with T2DM must be instructed on how this should be done.

Regular blood glucose monitoring is essential but not always feasible. The difficulty in matching the insulin treatment with the number of meals led the experts to recommend the use of either basal-bolus (preferred choice) or premix insulin (alternative), subject to patients' goals of care, acceptability, availability and affordability.

\section{DIGITAL FEATURES}

This article is published with digital features to facilitate understanding of the article. You can access the digital features on the article's associated Figshare page. To view digital features for this article go to https://doi.org/10.6084/m9. figshare.13128830.

\section{INTRODUCTION}

Type 2 diabetes mellitus (T2DM) is a rapidly growing public health problem in sub-Saharan Africa (SSA) and has a substantial impact on the continent's socioeconomic status $[1,2]$. Published data on diabetes in SSA reveals that its 
prevalence varies by region, ethnicity and economic development, ranging from $1 \%$ in Benin to over $12 \%$ in Seychelles, South Africa and Comoros [3]. An estimated 19.4 million adults aged $20-79$ years have diabetes in SSA and 28.6 million may be affected by diabetes by the year 2030 if current trends persist [3]. More than $50 \%$ of patients with diabetes in SSA are undiagnosed and likely to present with complications $[4,5]$. Several intrinsic characteristics, such as genetic predisposition, obesity and environmental factors, including urbanisation, high-calorie "Western diet" and lifestyle changes, have contributed to the rapid rise in the incidence of T2DM across SSA [6-9].

Access to diagnosis, treatment and care varies widely across the countries in the region [10]. Early detection and appropriate treatment of the disease and its complications are still a distant goal [10]. Recent studies show an increasing need for insulin therapy despite a wide array of oral glucose-lowering agents [11-13]. Existing guidelines on insulin therapy are limited by the lack of contextualisation [14]. There are gaps, particularly with regard to the initiation, maintenance and titration of insulin therapy based on the dietary patterns in this region. African cuisine is unique due to the striking difference in its composition and nutritional value relative to diets in the rest of the world $[15,16]$.

In this review, we hypothesise that there is a lack of information on how to modify insulin regimens to accomodate African cuisine. Here, we review current insulin therapy practices and propose a patient-centric guide to insulin therapy based on African cuisine. It is hoped that this paper will facilitate and contribute to the improvement of patients with T2DM consuming African cuisine.

This article is based on previously conducted studies and does not contain any studies with human participants or animals performed by any of the authors.

\section{Medical Need}

There are unmet needs in the guidance of insulin therapy in patients with T2DM in Africa.
Several factors, such as lack of knowledge (on insulin initiation and titration, individualisation of treatment), affordability and accessibility are barriers to the effective management of T2DM in SSA. A comprehensive review of the literature coupled with expert clinical opinion may help overcome some barriers. The experts reviewed the available evidence during an international kick-off meeting and provided their insights based on their clinical experience in the management of T2DM. Healthcare providers, especially primary care physicians, may use the evidence/expert opinion from this publication to complement clinical judgement.

\section{METHODOLOGY}

\section{Search Strategy}

The co-authors of this review, all diabetes experts who are predominantly from SSA, conducted a literature search using electronic medical databases-PubMed, African Journals Online, Directory of Open Access Journals and Google Scholar. The keywords included "Africa", "diet", "insulin", "sub-Saharan Africa" and "diabetes". Based on the abstracts retrieved, potentially relevant publications were identified and full-text articles extracted. Additional studies were assessed by the authors using their personal knowledge on this topic. No filters were used for the publication dates; however, filters were used to choose studies that were conducted in humans and published in English. Relevant cross-references and expert opinions were further used in the current review. A search string "insulin therapy" + "Africa" generated 56 references, of which 20 were deemed to be suitable for this review. Similarly, diabetes[Title] and management[Title] and sub[Title] and Saharan[Title] and Africa[Title] generated six results, all of which were considered relevant.

The Health Action International and International Diabetes Federation (IDF) websites were also searched for relevant information. In cases where there were divergent views on any salient matter, a vote was called among the experts and a simple majority was deemed 
acceptable for a decision to be reached. In addition to the literature search, experts among the authors who have participated in previous guidelines elsewhere were allowed to suggest a guide to the general house for consideration. The opinion of the experts is presented here.

\section{WHAT IS THE "AFRICAN CUISINE"?}

"African cuisine," although difficult to describe, mainly comprises starchy carbohydrates, vegetables and plant sources of fats. The diet varies significantly based on seasonality, country, culture, affordability and social status. Most ethnic cuisines in SSA contain starchy foods along with a sauce or soup. The starchy food is made from cereals, roots and tubers and can be labelled as a "CMT" (cereals, millets, tubers) diet [16-19]. The sauce or soup dip consists of a vegetable platter or dish made from legumes, meat or fish [17]. For example, in Kenya, maize is a staple food, accounting for $65 \%$ of the total staple caloric intake and $36 \%$ of total food caloric intake [18]. According to the first multicentre SSA Total Diet Study (SSA-TDS), 2328 commonly consumed foods can be pooled into 194 composite samples of cereals, tubers, legumes, vegetables, nuts and seeds, dairy, oils, beverages and miscellaneous [19, 20]. Africans consume less than one serving of fruits per day [17]. The overall consumption is generally restricted to locally sourced foods; the portions comprise high starch vegetables that pack approximately three- to four-fold more starchy carbohydrates than non-starchy types. Even within the same ethnic group, environmental factors influence the dietary pattern, as has been shown in the Research on Obesity and type 2 Diabetes among African Migrants (RODAM) study in Ghanaian migrants [21].

Inadequate knowledge of nutrients and nutrition, sociocultural habits, psychological and physiological attributes and local ecology affect food choices and meal patterns [19, 22]. In pastoral communities, for example, children spend $70 \%$ of their time herding livestock and, consequently, their main meal is the evening meal. In rural areas, the main meals are prepared in the evening and breakfast constitutes reheated leftovers [17]. The cost of production coupled with long and laborious domestic preparation methods have reduced the range of traditional foodstuff for everyday consumption [17]. However, the African region is currently undergoing a nutritional transition, with people increasingly consuming more energy-dense and ultra-processed foods with a high glycaemic load (GL) as well as sugar-sweetened beverages. This change is fueling the rise in metabolic disorders such as T2DM, obesity and cardiovascular diseases $[23,24]$.

\section{DIET AND BLOOD GLUCOSE}

Glycaemic index (GI) and GL are two measures used to classify foods based on acute postprandial glycaemic effects of nutrients. Although the GI correlates well with the carbohydrate content, the GI of mixed African meals may not adequately predict the digestibility index. Thus, certain mixed African meals with a low GI may still elicit significant postprandial hikes, possibly because of the large portions consumed per sitting. Consequently, although the typical mixed meal consumed in SSA may have a low GI, it may be associated with an exaggerated postprandial hyperglycaemia consequent to the high carbohydrate load of the meal. For example, carbohydrate-rich foods with a similar composition can cause different glycaemic responses and may have a different GI (Fig. 1) $[25,26]$. This concept has gained support from the World Health Organization, the American Diabetes Association (ADA), Diabetes UK and the Canadian Diabetes Association [27]. Glucose, with a GI of 100 , is taken as the reference; high GI foods are those containing carbohydrates that are digested, absorbed and metabolised quickly (GI $\geq 70$ on the glucose scale), whereas low GI foods take longer to be broken down and absorbed (GI $\leq 55$ on the glucose scale) [28]. Traditional foods were unprocessed, plant-based and high in fibre, and invariably had low GI. In contrast, most foods currently consumed are generally highly processed and have a high GI (Table 1).

To understand the impact of some of the commonly consumed food items on 


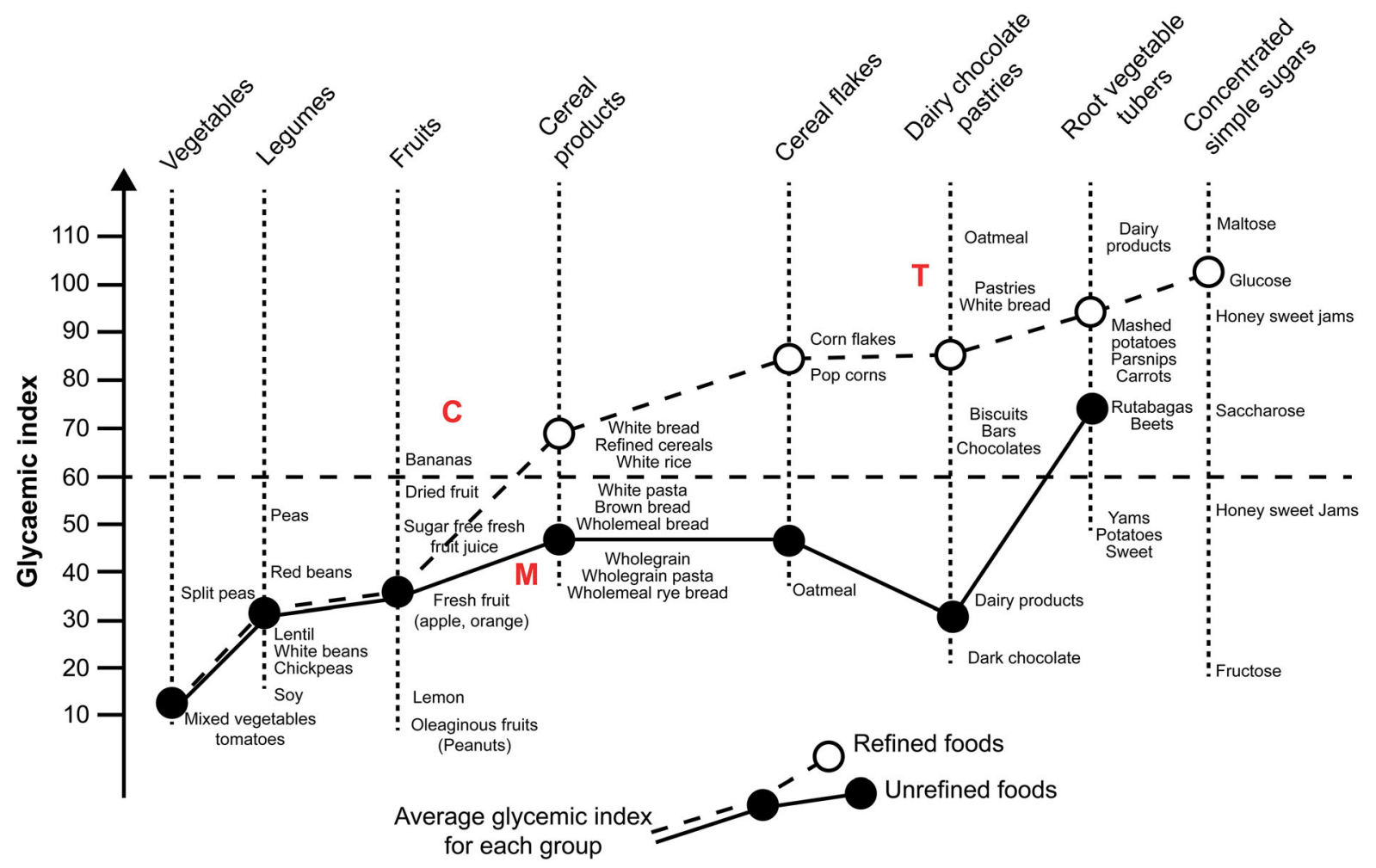

Fig. 1 Chart showing average glycaemic index (GI) for each group of food. $C$ Cereals, $M$ millets, $T$ tubers Adapted from: Augustin et al. [28], Schwingshackl et al. [60],
Haghighatdoost et al. [61], Alfenas et al. [62], Brouns et al. [63], Cherbut et al. [64], Wolever and Mehling [65] [66] postprandial glycaemia, it is important to take the concept of GI and GL into consideration. The GL is defined as: GI $\times$ carbohydrate (g) content per portion/100. As an example, Table 2 shows the relative contribution of commonly eaten foods (mostly starchy carbohydrates) in Nigeria to plasma glucose level [29]. Interestingly, GI values for different preparations of cassava (Manihot esculenta) range from 84 to 99 [29, 30], with the lowest GI noted in eba and the highest in starch (also called Usi in the local language of Southern Nigeria). Although both are derived from the same source (cassava), eba/gari is less processed than starch. The findings from this study underscore the importance of matching the insulin regimen to the meal plan [29]. In the African context, even though the foods may be minimally processed, the usual portions consumed per sitting tend to be enormous. Moreover, dietary intake is also influenced by shared plate eating, which is very common in Africa. Individual portion sizes are more difficult to assess in this context.

The carbohydrate load of a meal is the single most important predictor of postprandial blood glucose (PPBG) hikes [25]. The GL of a meal can be decreased by reducing the GI of the meal and/or by reducing the amount ingested [31]. The effect of carbohydrate-rich meals on blood glucose spikes is variable. For most meals, the blood glucose spikes generally occur between 45 and 90 min after starting the meal, although for some foods the blood glucose level may not peak until $4 \mathrm{~h}$ after starting the meal. The body mass index (BMI) also affects blood glucose spikes. In individuals with a normal BMI $\left(18.5-24.9 \mathrm{~kg} / \mathrm{m}^{2}\right)$, spikes occur within $60 \mathrm{~min}$ of the meal, while in overweight individuals (BMI $25.0-29.9 \mathrm{~kg} / \mathrm{m}^{2}$ ) the rise in blood glucose occurs after $90 \mathrm{~min}$ [32]. Low-GL diets help to control PPBG and are critical in slowing the 
Table 1 Glycaemic index of commonly consumed food in sub-Saharan Africa

\begin{tabular}{|c|c|c|c|}
\hline & Low GI foods (GI $\leq 55)$ & Medium GI foods (56-70) & High GI foods (> 70) \\
\hline Most non-starchy vegetable $<15$ & Canned baked beans 48 & White rice 56 & Bagel 72 \\
\hline Peanuts $<15$ & Green peas 48 & Pita bread 57 & Corn chips 72 \\
\hline Low-fat yogurt, no sugar $<15$ & Old-fashioned porridge 49 & Rice vermicelli 58 & Honey 73 \\
\hline Tomatoes 15 & Spaghetti white 50 & Pineapple 59 & Cheerios 74 \\
\hline Peas 22 & Orange 50 & Hamburger bun 61 & Doughnuts 75 \\
\hline Green lentils 22 & Mango 50 & Ice cream 61 & French fries 76 \\
\hline Kidney beans 24 & Yam 51 & Raisins 64 & Watermelon 76 \\
\hline Plum 24 & Sweet corn 52 & Popcorn 65 & Vanilla wafers 77 \\
\hline Grapefruit 25 & Orange juice 52 & Couscous 65 & Boiled potato 78 \\
\hline Barley 28 & Sweet corn 52 & Quick-cooking porridge 65 & White bread 79 \\
\hline Peach 28 & Banana 53 & Rye crisp-bread 65 & Jelly beans 80 \\
\hline Chick peas 28 & Potato chips 54 & Table sugar (sucrose) 65 & Pretzels 81 \\
\hline Fat-free milk 32 & Brown Rice 54 & Instant porridge 66 & Cornflakes 81 \\
\hline Pear 33 & Oatmeal cookies 55 & Millet porridge 67 & Rice cakes 82 \\
\hline Soy milk 34 & Plantain 55 & Croissant 67 & Mashed potatoes, instant 83 \\
\hline Sweet potato 35 & Sushi 55 & Soda/soft drinks 68 & Mashed potatoes 87 \\
\hline Apple 36 & & Whole wheat bread 68 & Rice, instant 91 \\
\hline Whole wheat spaghetti 37 & & Wheat flake biscuit 69 & French broad 95 \\
\hline Green gram dhal 38 & & Breadfruit 68 & Lucozade 95 \\
\hline Tomato soup 38 & & White wheat bread 75 & Parsnips 97 \\
\hline Carrots, cooked 39 & & & Dates 100 \\
\hline \multicolumn{4}{|l|}{ Grapes 43} \\
\hline \multicolumn{4}{|l|}{ Macaroni 45} \\
\hline \multicolumn{4}{|l|}{ Banana bread 47} \\
\hline \multicolumn{4}{|l|}{ Long-grain rice 47} \\
\hline Bulgur wheat 48 & & & \\
\hline
\end{tabular}

Adapted from: Atkinson et al. [27]; Foster-Powell et al. [67]; Jenkins et al. [68]; Kaur et al. [69]

GI Glycaemic index

progression of T2DM as well as the development of its complications [33]. A diet is considered to be a low carbohydrate diet if the total carbohydrate intake is between 50 and $130 \mathrm{~g}$ and accounts for $10-20 \%$ of the total calorie intake/day; a high carbohydrate diet is one where the total carbohydrate intake is $>225 \mathrm{~g}$ /day and accounts for $>45 \%$ of total calories intake/day [34]. The authors of a systematic review reported that diets rich in 
Table 2 Glycaemic index and glycaemic load of some common Nigerian processed starchy foods

\begin{tabular}{lll}
\hline Food samples & Glycaemic index & Glycaemic load \\
\hline Starch (cassava) & $98.60 \pm 2.68$ & $49.30 \pm 3.5$ \\
Eba (cassava) & $82.25 \pm 0.05$ & $41.13 \pm 3.3$ \\
Amala (yam) & $84.35 \pm 2.68$ & $42.18 \pm 4.2$ \\
Agidi (maize) & $92.30 \pm 0.05$ & $46.15 \pm 3.1$ \\
Tuwo Masara (maize) & $86.80 \pm 0.5$ & $43.40 \pm 1.5$ \\
Tuwo Gero (millet) & $93.60 \pm 2.25$ & $46.80 \pm 3.4$ \\
Tuwo Dawa (sorghum) & $85.30 \pm 1.05$ & $42.65 \pm 3.2$ \\
Tuwo Shinkafa (rice) & $95.30 \pm 1.25$ & $47.65 \pm 2.2$ \\
Semovita (wheat) $+10 \%$ corn supplement & $95.80 \pm 0.28$ & $47.90 \pm 2.5$ \\
Semolina (wheat) & $95.28 \pm 0.04$ & $47.64 \pm 1.5$ \\
\hline
\end{tabular}

Adapted from Omoregie ES [29]

Values are presented as the mean \pm standard error of mean.

vegetables, fish and poultry and devoid of red meat, processed foods and starchy carbohydrates may retard the progression of T2DM and prevent morbidity [35].

\section{EXISTING PRACTICES AND HINDRANCES IN THE MANAGEMENT OF T2DM IN SSA}

The management of T2DM in SSA is suboptimal for several reasons, including socioeconomic factors, healthcare-related factors, patient-related factors and lack of knowledge (especially in terms of education on the insulin injection technique and titration of insulin doses). The healthcare costs associated with the management of T2DM are very high and may not be affordable to the general population. Healthcare systems are ill-equipped for dealing with the increasing burden of the disease and its complications. Challenges include-but are not limited to-unavailability of equipment for disease diagnosis and monitoring [5], insufficient number of qualified and trained healthcare providers (doctors, nurses, dieticians and peer educators), scarcity of available treatments, unavailability of locally appropriate guidelines and few disease registries. Primary healthcare systems are largely underdeveloped and home-based screening, treatment and monitoring are rarely available. This in turn leads to limited screening, with a large number of patients remaining undiagnosed until complications arise. Among patients known to have T2DM, structured diabetes self-management education and drugs are unavailable, facilities to manage complications are restricted and available options are economically taxing [36].

The failure of primary care physicians to initiate and titrate insulin (for several reasons, including the lack of adequate training) is another major barrier in the management of hyperglycaemia $[37,38]$. It is usual for healthcare providers to refer patients to specialists for insulin initiation and intensification. There is a lack of information on carbohydrate counting, on how to modify insulin regimens to suit the pattern/composition of the African cuisine and on how to monitor patients and therefore titrate insulin doses. 


\section{INSULIN THERAPY AND MANAGEMENT OF HYPERGLYCAEMIA IN AFRICA}

In SSA, the consumption of a cuisine high in starchy vegetable content is the status quo. Healthcare providers must empower patients to modify this habit. Until the patient has successfully changed this status quo, insulin therapy must be tailored to match it. The East Africa Diabetes Study Group (EADSG) recommends initiating insulin therapy as early as required to manage hyperglycaemia, with a view of minimising and delaying the risk of long-term complications in patients uncontrolled by diet and oral antihyperglycaemic agents (OHAs) [39]. Insulin therapy is considered as monotherapy or in combination therapy with OHAs when glycated haemoglobin (HbA1c) is $\geq 7.5 \%(\geq 58 \mathrm{mmol} / \mathrm{mol})$ and for those with $\mathrm{HbA} 1 \mathrm{c} \geq 10 \%$ ( $\geq 86 \mathrm{mmol} / \mathrm{mol})$.

Several options exist for the initiation of insulin. A long-acting (basal) insulin or biphasic insulin administered once or twice daily may be used when initiating insulin therapy. Insulin may be given alone, in combination with insulin potentiators, such as glucagon-like peptide-1 receptor agonists or in combination with OHAs. If the glycaemic targets remain unmet, basal insulin therapy may also be intensified with rapid-acting or short-acting (bolus or prandial) insulin that is given at mealtime to control the anticipated rise in PPBG. In all cases, the insulin regimen should be adapted and individualised based on the patient's preferences, caloric and carbohydrate content of meals, physical activity, body weight and comorbidities. Global consensus guidelines suggest using basal insulin, with its lower acquisition cost, when cost is a major issue in selecting appropriate insulin therapy. For intensification, they advise adding bedtime Neutral Protamine Hagedorn (NPH) insulin $[40,41]$. Detailed guidelines on the insulin regimen that should be used for initiation and intensification are available; however, there are no recommendations on how to customise the regimen to variability in meal patterns.
Across Africa, access to diabetes medications, including insulin, is low [42]. A recent microsimulation study reported that only one in seven people in Africa will have access to insulin, while overall global accessibility is one in two people $[43,44]$. Case studies from Mozambique and Zambia show that there are issues with the equitable distribution of insulin as well as the availability of syringes and testing equipment [45]. The cost of a month's supply of insulin in Malawi is the equivalent of 19.6 days of wages (minimum wage) [46], while in Tanzania, it represents $25 \%$ of the minimum wage [47].

\section{INSULIN MANAGEMENT FOR THE HIGH CARBOHYDRATE DIET PREVALENT IN SSA: EXPERTS' OPINION}

Dietary habits play an important role in initiating and achieving optimim insulin therapy. In this paper, we have classified the carbohydrate load in the meal as the percentage of the meal consisting of CMT. A very high carbohydrate load is when $>50 \%$ of the meal consists of CMT; a high carbohydrate load is when between 25 and $50 \%$ of the meal consists of CMT; and a moderate load is when $<25 \%$ of the meal consists of CMT. Alternate methods for quantifying total carbohydrate load (both starchy and non-starchy) include counting in 1-g increments, 10 -g portions or 15-g exchanges [48]. A meal is considered to be a "full meal" when the carbohydrate content is $\geq 30 \mathrm{~g}$, whereas meals with a carbohydrate content of $<30 \mathrm{~g}$ are considered to be snacks.

The selection of the most appropriate insulin regimen (type and timing of the insulin) for an individual is central to efficient diabetes management because good glycaemic control early in the disease is associated with better microvascular outcomes [49, 50]. Guidelines recommend initiating insulin therapy with basal insulin (ADA; American Association of Clinical Endocrinologists) $[50,51]$ or premixed insulins (IDF) [52] as per clinical judgement. Currently, insulin regimens for the initiation or 
intensification of therapy are based on subjective decisions as there are no specific guidelines on how to determine what the ideal regimen should be. This is the need of the hour. Based on our collective clinical experience and expertise, we have made some recommendations (Table 3) that will enable healthcare providers to choose the appropriate insulin therapy/regimen depending on the frequency of meals and the carbohydrate content of those meals. The different insulin regimens are discussed in detail in the following paragraphs.

The basal-bolus regimen mimics normal physiology better than premixed insulin and is also associated with more stringent glycaemic control, lower post-meal glucose spikes and more convenient mealtime administration. A basal-bolus regimen with flexible insulin dosing based on the carbohydrate content of each meal offers the best opportunity for managing PPBG spikes [53]. Basal-bolus therapies also improve the time in range and therefore result in better patient outcomes in terms of prevention of complications (e.g. diabetic retinopathy) [54]. Basal-bolus insulin may therefore be a preferred option for the initiation of insulin therapy. However, basal-bolus therapy is associated with a higher risk of hypoglycaemia, necessitating more frequent glucose monitoring [55]. HbA1c, self-monitored blood glucose (SMBG) levels and the time in range, where available, should be considered as important parameters in adjusting insulin doses.

Premix insulin is proposed as an alternative for insulin initiation. This recommendation takes into account the diverse healthcare systems across SSA, the experience of healthcare providers and patient factors, such as the ability to do home glucose monitoring and the need for more frequent injections with a basal-bolus regimen. Limited resources, availability of healthcare services, financial constraints and improved adherence are factors that favour the use of premixed insulin. The use of premixed insulin requires consistency in both meal patterns and lifestyle [56]. The insulin regimen can be adjusted to suit the frequency of full meals, once daily (OD) (in patients taking a single full meal per day) or twice daily (BD) (in patients taking two or three full meals per day).
Especially in low-resource contexts, the use of a premix insulin regimen offers several advantages over basal-bolus regimes, such as fewer injection requirements, simpler administration and reduced need for frequent SBGM and its associated costs. If analogue premix insulins are used, the time interval between two doses of premixed will vary and can be shorter than with basal-bolus insulin.

The healthcare providers can prescribe either of the two recommended regimens presented in Table 3 depending on patient factors and healthcare facilities. The starting dose for basalinsulin is $10 \mathrm{U} /$ day or $0.1-0.2 \mathrm{U} / \mathrm{kg} /$ day, and the dose can be adjusted by $10-15 \%$ once or twice weekly to reach the FPG target. The frequency of full meals will determine the prandial insulin regimen (once daily, twice daily or three times daily). Starting dose for meal-time insulin is $10 \%$ of the basal dose, which can be adjusted by $10-15 \%$ once or twice weekly to achieve PPBG targets. The pre-mix dosing regimen also depends on the frequency of full meals (once daily or twice daily). The starting dose for premixed insulin is $0.1-0.2 \mathrm{U} / \mathrm{kg} /$ day when taken OD, $0.3-0.4 \mathrm{U} / \mathrm{kg} /$ day in equally divided doses (BD) when the patient takes two full meals and $0.5 \mathrm{U} / \mathrm{kg} /$ day in equally divided doses (BD) when the patient takes three full meals. The dose titrations to achieve glycaemic targets and to manage hypoglycaemia are presented in detail in Table 3.

The choice of the insulin regimen must be individualised. In addition to focusing on blood glucose levels, the decision needs to be tailored to the individual patient's lifestyle and requirements. The timing and constituents of meal portion sizes, GL and GI should all be taken into account. At all times, there must be assessments of individual needs and all comorbidities considered to be part of providing comprehensive diabetes care.

\section{DISCUSSION}

With increasing westernisation of SSA, traditional dietary patterns characterized by a low GI have been largely replaced by highly processed foods, thus compounding the problem of 


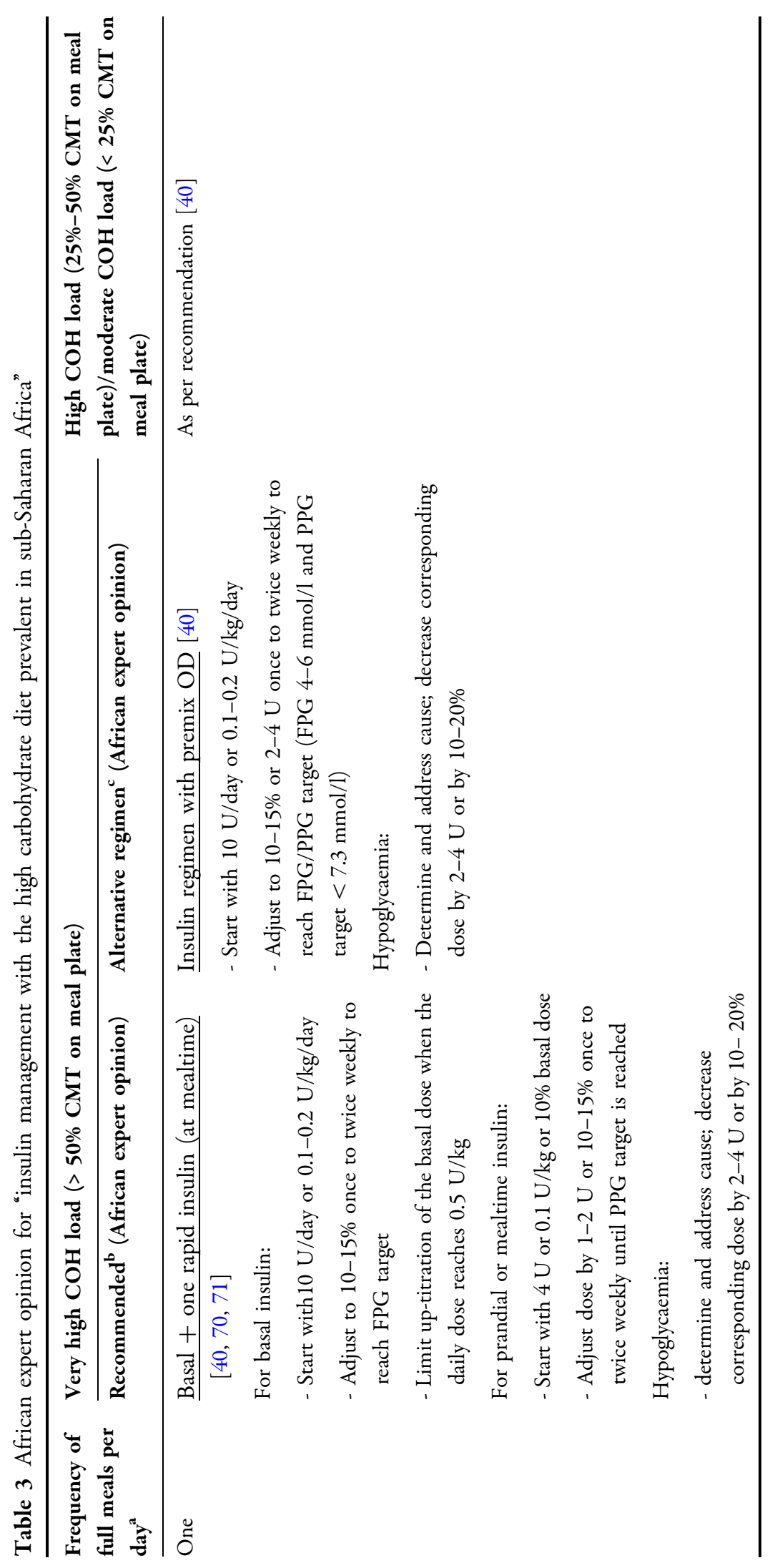




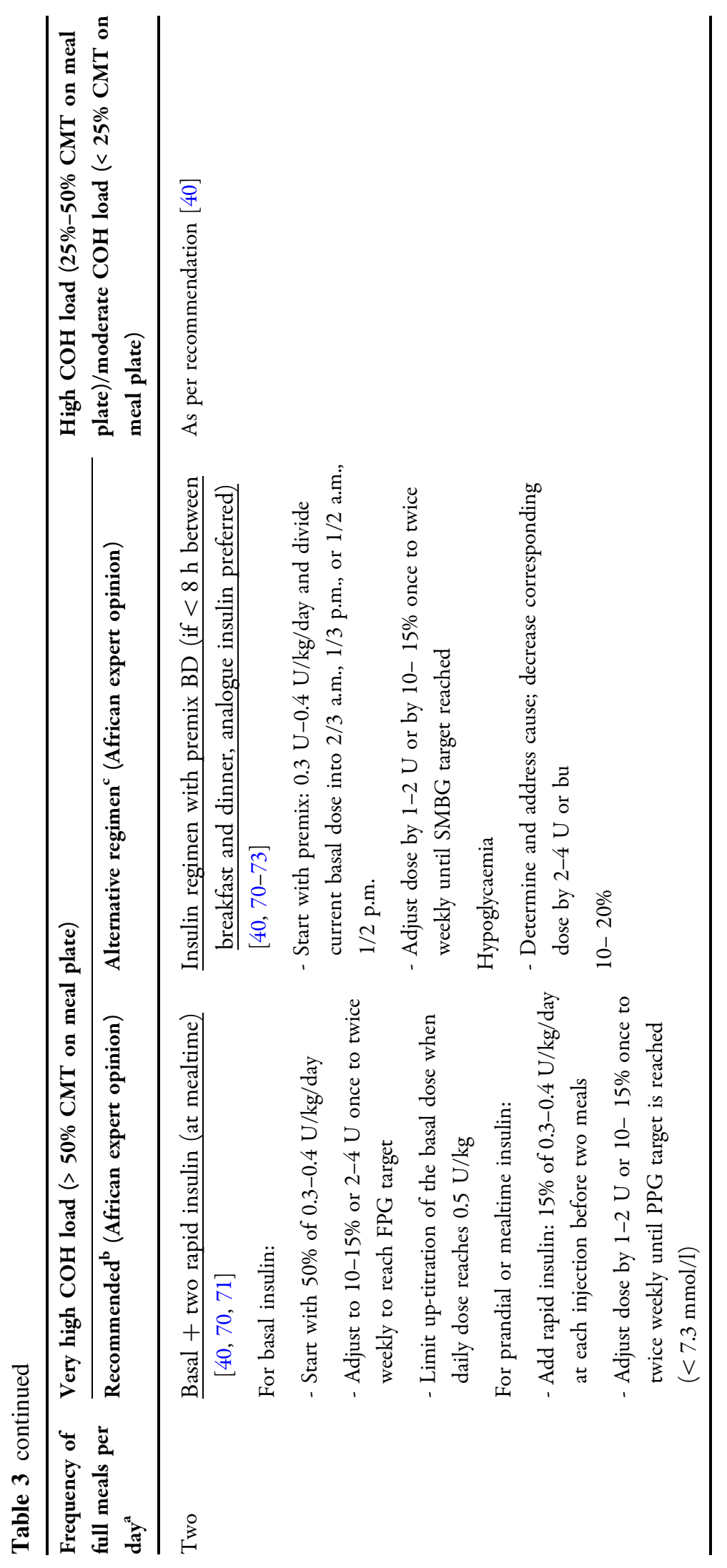




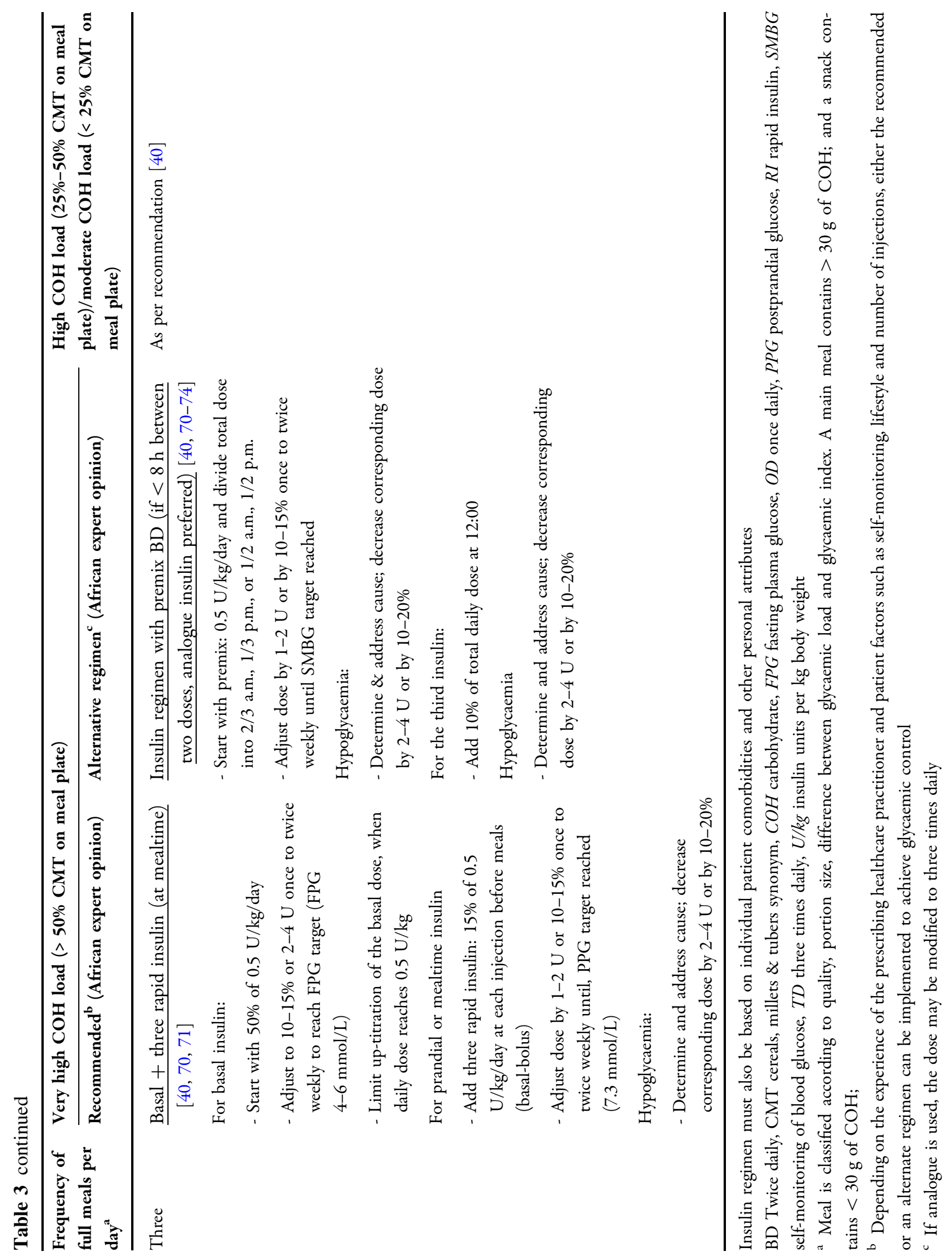


obesity-driven diabetes. Traditional African cuisine contains starchy food made from CMT along with a sauce or dip. Meal patterns vary widely across Africa, but a preference for meals high in CMT cuts across the continent [17]. In their study on obesity and diabetes in African migrants, Boeteng et al. found that a 'rice, pasta, meat and fish' diet was inversely associated with the 10-year atherosclerotic cardiovascular disease risk (ASCVD), while a 'root, tubers and plantain diet' was directly associated with increased 10-year ASCVD risk [24]. Even though consumption patterns in SSA are often restricted to locally obtained foods having a relatively low GI, the usual amounts/portions consumed per sitting are large, resulting in large post-meal glucose spikes and suboptimal postprandial control.

The inability of patients to afford home glucose monitoring and inadequate knowledge of insulin initiation and titration regimens further compound the problem of postprandial hyperglycaemia. It has been demonstrated that postprandial hyperglycaemia confers an increased risk of diabetes complications and poor outcomes $[57,58]$.

An important objective in diabetes management is to control blood glucose levels. Good glycaemic control early in the disease delays the onset and progression of chronic complications of diabetes. These benefits persist for several years, even after the initial tight glycaemic control is lost $[49,59]$. Sustaining changes in eating patterns is difficult, more so in countries with fragmented healthcare systems. Healthcare providers must understand the sociocultural dimensions influencing food choices and make context-specific dietary modifications for their patients. Emphasis must be placed on locally available low GI foods, especially non-starchy vegetables, healthy fats from fish and nuts and lean protein. Healthcare providers must also recognize that behavior modification takes time, may have a relapsing and remitting course and indeed may never be achieved by some patients. Many individuals in SSA will likely continue with a high CMT dietary habit.

Insulin therapy is often needed to manage T2DM, and the insulin regimen should be optimised for each patient, with a particular focus on the starchy carbohydrate content of the patient's meals. African cuisine accentuates the need for insulin regimens and preparations to be tailored to existing dietary patterns and preferences. Primary care physicians working in SSA often fail to initiate and optimise insulin therapy, largely due to an inadequate knowledge of and limited access to insulin, as well as a hesitation to prescribe this medication.

The basal-bolus regime is preferred for tight glycaemic control; however, several challenges common to the low-income countries of Africa make premixed insulin a more practical choice for glucose control. For optimal glycaemic control, the basal-bolus regime is the ideal firstchoice therapy. Basal-bolus mimics normal physiology better than premixed insulin and has the additional advantages of providing more stringent glycaemic control, better managing post-meal spikes and being more convenient for mealtime administration. However, there are some limitations to its use, such as the need for frequent injections and for extra arrangements and preparations for carrying and injecting the insulin, as well as an increased risk for hypoglycaemia. Alternatively, premixed insulin can be used. In addition, given the huge variability in the diet across regions in SSA, these recommendations are also suitable for SSA regions that have seen a shift to the westernized dietary habits.

We wish to emphasize that the scenario in SSA is complex due to diverse healthcare systems, variable levels of expertise of caregivers and patients with a wide spectrum of presentation of diabetes and socioeconomic classes, among others. The recommendations provided here are derived from the best available options in the region, clinical experience, and suggestions from literature. The author group, however, did not use any tools (Delphi, Likert scale) to arrive at the recommendations, which is a limitation of the study. However, the the authors do agree that a detailed clinical consensus recommendation taking into account the healthcare systems in SSA and associated costs is a necessity and will be taken up as a sequel to the current study. The suggested options may or may not be feasible in all circumstances. As such, these recommendations 
cannot replace the independent judgement of physicians and their institutions.

\section{CONCLUSION}

"African cuisine" is varied and routinely consists of large portions of starchy carbohydrates. Recent years has seen a progressive change in dietary habits in SSA due to urbanisation and cultural adaptations. Recognising and studying these eating patterns in order to determine carbohydrate content is crucial to achieve good glycaemic control. Heathcare providers who treat people with diabetes should empathize with their patients and work with them to accept that modification of dietary habits forms the foundation of good diabetes management. It is important to match insulin requirements with the total carbohydrate content of meals and specifically to the GL. Although of all insulin treatments basal-bolus regimes mimic normal physiology most closely, challenges specific to the African continent make premixed insulin an acceptable alternative.

\section{ACKNOWLEDGMENTS}

Funding. The Journal's rapid service fee was supported by Novo Nordisk. The study was funded by Novo Nordisk.

Medical Writing and Editorial Assistance. The authors thank Amit Garg and Aafrin Khan from Enago Life Sciences, India, for providing medical writing support which was funded by Novo Nordisk in accordance with Good Publication Practice (GPP3) guidelines.

Authorship. All named authors meet the International Committee of Medical Journal Editors (ICMJE) criteria for authorship for this manuscript, take responsibility for the integrity of the work as a whole, and have given final approval for the version to be published.

Disclosures. Jean Claude Mbanya reports grants and/or personal fees for educational, advisory, and research activities from GSK, Lilly, Novartis, Novo Nordisk, Sanofi, and Servier. Roberta Lamptey reports grants and/or personal fees for educational, advisory activities from Novo Nordisk, Sanofi, AstraZeneca, BI and Novartis. Andrew E. Uloko reports personal fees for educational, advisory activities from Novo Nordisk, Novartis, Sanofi, Servier and Astra Zeneca. Amos Ankotche reports grants and/or personal fees for educational and advisory activities from Novo Nordisk, Servier, Novartis, Astra Zeneca, Sanofi, Merck and Pfizer. Gontle Moleele and Gaman Ali Mohamed report advisory and speaking engagements from major pharmaceutical companies outside the submitted work. Iswaraj Ramracheya reports personal fees for educational, advisory activities from Novo Nordisk, Sanofi, and Janssen. Kaushik Ramaiya and Malusi Ndiweni have no conflicts of interest to declare. Maïmouna Ndour Mbaye reports fees as speaker from Novo Nordisk, Sanofi, Novartis, Servier. Silver Bahendeka reports honoraria from AstraZeneca and Sanofi. Sanjay Kalra reports honoraria from Eli Lilly, Novo Nordisk and Sanofi.

Compliance with Ethics Guidelines. This article is based on previously conducted studies and does not contain any studies with human participants or animals performed by any of the authors.

Data Availability. Data sharing is not applicable to this article as no datasets were generated or analysed during the current study.

Open Access. This article is licensed under a Creative Commons Attribution-NonCommercial 4.0 International License, which permits any non-commercial use, sharing, adaptation, distribution and reproduction in any medium or format, as long as you give appropriate credit to the original author(s) and the source, provide a link to the Creative Commons licence, and indicate if changes were made. The images or other third party material in this article are included in the article's Creative Commons licence, unless indicated otherwise in a credit line to the material. If material is not included in the article's Creative 
Commons licence and your intended use is not permitted by statutory regulation or exceeds the permitted use, you will need to obtain permission directly from the copyright holder. To view a copy of this licence, visit http:// creativecommons.org/licenses/by-nc/4.0/.

\section{REFERENCES}

1. Cikomola JC, Kishabongo AS, Speeckaert MM, et al. Diabetes mellitus and laboratory medicine in subSaharan Africa: challenges and perspectives. Acta Clin Belg. 2019;74:137-42.

2. Mbanya JC, Motala AA, Sobngwi E, et al. Diabetes in sub-Saharan Africa. Lancet. 2010;375:2254-66.

3. Williams R, Colagiuri S, Almutairi R, et al. IDF diabetes atlas. 2019;2020:1-176.

4. Uloko AE, Ofoegbu EN, Chinenye S, et al. Profile of Nigerians with diabetes mellitus-Diabcare Nigeria Study Group (2008): results of a multicenter study. Indian J Endocrinol Metab. 2012;16(4):558-64. (Erratum in: Indian J Endocrinol Metab. 2012;16(6): 981).

5. Pastakia SD, Pekny CR, Manyara SM, et al. Diabetes in sub-Saharan Africa-from policy to practice to progress: targeting the existing gaps for future care for diabetes. Diabetes Metab Syndr Obes. 2017;10: 247-63.

6. Steyn NP, McHiza ZJ. Obesity and the nutrition transition in Sub-Saharan Africa. Ann NY Acad Sci. 2014;1311:88-101.

7. Jackson M, Walker S, Cruickshank JK, et al. Diet and overweight and obesity in populations of African origin: Cameroon, Jamaica and the UK. Public Health Nutr. 2007;10:122-30.

8. Ekoru K, Young EH, Adebamowo C, et al. H3Africa multi-centre study of the prevalence and environmental and genetic determinants of type 2 diabetes in sub-Saharan Africa: study protocol. Glob Health Epidemiol Genom. 2016;1:e5-e5.

9. Meeks KAC, Henneman P, Venema A, et al. Epigenome-wide association study in whole blood on type 2 diabetes among sub-Saharan African individuals: findings from the RODAM study. Int J Epidemiol. 2019;48:58-70.

10. Manne-Goehler J, Atun R, Stokes A, et al. Diabetes diagnosis and care in sub-Saharan Africa: pooled analysis of individual data from 12 countries. Lancet Diabetes Endocrinol. 2016;4:903-12.

11. Tabesh M, Magliano DJ, Tanamas SK, et al. Diabetes management and treatment approaches outside of North America and West Europe in 2006 and 2015. Acta Diabetol. 2019;56:889-97.

12. Roglic G, Norris SL. Medicines for treatment intensification in type 2 diabetes and type of insulin in type 1 and type 2 diabetes in low-resource settings: synopsis of the World Health Organization guidelines on second- and third-line medicines and type of insulin for the control of blood glucose levels in nonpregnant adults with diabetes mellitus. Ann Intern Med. 2018;169:394-7.

13. Mariye T, Girmay A, Birhanu T, et al. Adherence to insulin therapy and associated factors among patients with diabetes mellitus in public hospitals of Central Zone of Tigray, Ethiopia, 2018: a crosssectional study. Pan Afr Med J. 2019;33:309.

14. Owolabi MO, Yaria JO, Daivadanam M, et al. Gaps in guidelines for the management of diabetes in low- and middle-income versus high-income countries-a systematic review. Diabetes Care. 2018;41:1097-105.

15. Sharma S, Mbanya JC, Cruickshank K, et al. Nutritional composition of commonly consumed composite dishes from the Central Province of Cameroon. Int J Food Sci Nutr. 2007;58:475-85.

16. Lamptey R, Velayoudom FL, Kake A, et al. Plantains: gluco-friendly usage. J Pak Med Assoc. 2019;69: $1565-7$.

17. Oniang'o RK, Mutuku JM, Malaba SJ. Contemporary African food habits and their nutritional and health implications. Asia Pac J Clin Nutr. 2003;12: $331-6$.

18. Mohajan HK. Food and nutrition scenario of Kenya. Am J Food Nutr. 2014;2:28-38.

19. Raschke V, Oltersdorf U, Elmadfa I, et al. Content of a novel online collection of traditional east African food habits (1930s-1960s): data collected by the Max-Planck-Nutrition Research Unit, Bumbuli, Tanzania. Asia Pac J Clin Nutr. 2007;16:140-51.

20. Ingenbleek L, Sulyok M, Adegboye A, et al. Regional Sub-Saharan Africa total diet study in Benin, Cameroon, Mali and Nigeria reveals the presence of 164 mycotoxins and other secondary metabolites in foods. Toxins (Basel). 2019; 11(1):54. https://doi. org/10.3390/toxins11010054.

21. Galbete C, Nicolaou M, Meeks KA, et al. Food consumption, nutrient intake, and dietary patterns 
in Ghanaian migrants in Europe and their compatriots in Ghana. Food Nutr Res. 2017;61:1341809.

22. McCann JC. Stirring the pot-a history of African cuisine. Athens: Ohio University Press; 2009.

23. Bosu WK. An overview of the nutrition transition in West Africa: implications for non-communicable diseases. Proc Nutr Soc. 2015;74:466-77.

24. Boateng D, Galbete C, Nicolaou M, et al. dietary patterns are associated with predicted 10-year risk of cardiovascular disease among ghanaian populations: the research on obesity and diabetes in African Migrants (RODAM) Study. J Nutr. 2019;149: 755-69.

25. Mbanya JC, Mfopou JK, Sobngwi E, et al. Metabolic and hormonal effects of five common African diets eaten as mixed meals: the Cameroon Study. Eur J Clin Nutr. 2003;57:580-5.

26. Mbanya JC, Assah FK, Saji J, et al. Obesity and type 2 diabetes in Sub-Sahara Africa. Curr Diab Rep. 2014;14:501.

27. Atkinson FS, Foster-Powell K, Brand-Miller JC. International tables of glycemic index and glycemic load values: 2008. Diabetes Care. 2008;31:2281-3.

28. Augustin LSA, Kendall CWC, Jenkins DJA, et al. Glycemic index, glycemic load and glycemic response: an International Scientific Consensus Summit from the International Carbohydrate Quality Consortium (ICQC). Nutr Metab Cardiovasc Dis. 2015;25:795-815.

29. Omoregie ES, Osagie AU. Glycemic indices and glycemic load of some Nigerian foods. Pak J Nutr. 2008;7:710-6.

30. Okafor EN, Erukainure OL, Ozumba AU, et al. Cassava flour substitution modulates glycemic responses and glycemic index of wheat breads in apparent healthy volunteers. J Diet Suppl. 2017;14:446-52.

31. Lunde MSH, Hjellset VT, Holmboe-Ottesen G, et al. Variations in postprandial blood glucose responses and satiety after intake of three types of bread. J Nutr Metab. 2011;2011:437587.

32. Yalçın T, Al A, Rakıcıoğlu N. The effects of meal glycemic load on blood glucose levels of adults with different body mass indexes. Indian J Endocrinol Metab. 2017;21:71-5.

33. Blaak EE, Antoine JM, Benton D, et al. Impact of postprandial glycaemia on health and prevention of disease. Obes Rev. 2012;13:923-84.

34. Feinman RD, Pogozelski WK, Astrup A, et al. Dietary carbohydrate restriction as the first approach in diabetes management: critical review and evidence base. Nutrition. 2015;31:1-13.

35. Esposito K, Kastorini CM, Panagiotakos DB, et al. Prevention of type 2 diabetes by dietary patterns: a systematic review of prospective studies and metaanalysis. Metab Syndr Relat Disord. 2010;8:471-6.

36. Atun R, Davies JI, Gale EAM, et al. Diabetes in subSaharan Africa: from clinical care to health policy. Lancet Diabetes Endocrinol. 2017;5:622-67.

37. Zimmermann M, Bunn C, Namadingo $H$, et al. Experiences of type 2 diabetes in sub-Saharan Africa: a scoping review. Glob Health Res Policy. 2018;3:25-25.

38. Ng CJ, Lai PS, Lee YK, et al. Barriers and facilitators to starting insulin in patients with type 2 diabetes: a systematic review. Int J Clin Pract. 2015;69: 1050-70.

39. Silver B, Ramaiya K, Andrew SB, et al. EADSG guidelines: insulin therapy in diabetes. Diabetes Ther. 2018;9:449-92.

40. American Diabetes Association. Standards of medical care in diabetes-2020 abridged for primary care providers. Clin Diabetes. 2020;38:10-38

41. Davies MJ, D'Alessio DA, Fradkin J, et al. Management of hyperglycaemia in type 2 diabetes, 2018. A consensus report by the American Diabetes Association (ADA) and the European Association for the Study of Diabetes (EASD). Diabetologia. 2018;61: 2461-98.

42. Hall V, Thomsen RW, Henriksen O, et al. Diabetes in Sub Saharan Africa 1999-2011: epidemiology and public health implications. A systematic review. BMC Public Health. 2011;11:564-564.

43. Basu S, Yudkin JS, Kehlenbrink S, et al. Estimation of global insulin use for type 2 diabetes, 2018-30: a microsimulation analysis. Lancet Diabetes Endocrinol. 2019;7:25-33.

44. Beran D, Laing RO, Kaplan W, et al. A perspective on global access to insulin: a descriptive study of the market, trade flows and prices. Diabet Med. 2019;36:726-33.

45. Beran D, Yudkin JS, de Courten M. Access to care for patients with insulin-requiring diabetes in developing countries: case studies of Mozambique and Zambia. Diabetes Care. 2005;28:2136-40.

46. Mendis S, Fukino K, Cameron A, et al. The availability and affordability of selected essential medicines for chronic diseases in six low- and middle-income countries. Bull World Health Organ. 2007;85:279-88. 
47. Neuhann HF, Warter-Neuhann C, Lyaruu I, et al. Diabetes care in Kilimanjaro region: clinical presentation and problems of patients of the diabetes clinic at the regional referral hospital-an inventory before structured intervention. Diabet Med. 2002;19:509-13.

48. Bell KJ, King BR, Shafat A, et al. The relationship between carbohydrate and the mealtime insulin dose in type 1 diabetes. J Diabetes Complic. 2015;29:1323-9.

49. Holman RR, Paul SK, Bethel MA, et al. 10-year follow-up of intensive glucose control in type 2 diabetes. N Engl J Med. 2008;359:1577-89.

50. American Diabetes Association. Standards of medical care in diabetes-2018. Diabetes Care. 2018;41(1):S1-155.

51. Handelsman Y, Bloomgarden ZT, Grunberger G, et al. American association of clinical endocrinologists and american college of endocrinology clinical practice guidelines for developing a diabetes mellitus comprehensive care plan - 2015. Endocr Pract. 2015;21(Suppl 1):1-87.

52. International Diabetes Federation Guideline Development Group. Global guideline for type 2 diabetes. Diabetes Res Clin Pract. 2014;104(1):1-52

53. Candido R, Wyne K, Romoli E. A review of basalbolus therapy using insulin glargine and insulin lispro in the management of diabetes mellitus. Diabetes Ther. 2018;9:927-49.

54. Lu J, Ma X, Zhou J, et al. Association of time in range, as assessed by continuous glucose monitoring, with diabetic retinopathy in type 2 diabetes. Diabetes Care. 2018;41:2370-6.

55. Christensen MB, Gotfredsen A, Nørgaard K. Efficacy of basal-bolus insulin regimens in the inpatient management of non-critically ill patients with type 2 diabetes: a systematic review and meta-analysis. Diabetes Metab Res Rev. 2017;33(5). https://doi. org/10.1002/dmrr.2885.

56. Kalra S, Czupryniak L, Kilov G, et al. Expert opinion: patient selection for premixed insulin formulations in diabetes care. Diabetes Ther. 2018;9: 2185-99.

57. Moghissi ES, Korytkowski MT, DiNardo M, et al. American Association of clinical endocrinologists and American Diabetes Association consensus statement on inpatient glycemic control. Diabetes Care. 2009;32:1119-31.

58. Monnier L, Colette C. Glycemic variability: should we and can we prevent it? Diabetes Care. 2008;31(Suppl 2):S150-154.
59. Stratton IM, Adler AI, Neil HA, et al. Association of glycaemia with macrovascular and microvascular complications of type 2 diabetes (UKPDS 35): prospective observational study. BMJ. 2000;321: 405-12.

60. Schwingshackl L, Hoffmann G. Long-term effects of low glycemic index/load vs. high glycemic index/ load diets on parameters of obesity and obesity-associated risks: a systematic review and meta-analysis. Nutr Metab Cardiovasc Dis. 2013;23:699-706.

61. Haghighatdoost F, Azadbakht L, Keshteli AH, et al. Glycemic index, glycemic load, and common psychological disorders. Am J Clin Nutr. 2016;103:201-9.

62. Alfenas RC, Mattes RD. Influence of glycemic index/load on glycemic response, appetite, and food intake in healthy humans. Diabetes Care. 2005;28:2123-9.

63. Brouns F, Bjorck I, Frayn KN, et al. Glycaemic index methodology. Nutr Res Rev. 2005;18:145-71.

64. Cherbut C, Aube AC, Mekki N, et al. Digestive and metabolic effects of potato and maize fibres in human subjects. Br J Nutr. 1997;77:33-46.

65. Wolever TM, Mehling C. High-carbohydrate-lowglycaemic index dietary advice improves glucose disposition index in subjects with impaired glucose tolerance. Br J Nutr. 2002;87:477-87.

66. Wolever TM, Mehling C. Long-term effect of varying the source or amount of dietary carbohydrate on postprandial plasma glucose, insulin, triacylglycerol, and free fatty acid concentrations in subjects with impaired glucose tolerance. Am J Clin Nutr. 2003;77:612-21.

67. Foster-Powell K, Miller JB. International tables of glycemic index. Am J Clin Nutr. 1995;62:871S890 s.

68. Jenkins D, Wolever T, Taylor RH, et al. Glycemic index of foods: a physiological basis for carbohydrate exchange. Am J Clin Nutr. 1981;34:362-6.

69. Kaur B, Ranawana V, Henry J. The glycemic index of rice and rice products: a review, and table of $\mathrm{Gi}$ values. Crit Rev Food Sci Nutr. 2016;56:215-36.

70. Aschner P, Sethi B, Gomez-Peralta F, et al. Insulin glargine compared with premixed insulin for management of insulin-naïve type 2 diabetes patients uncontrolled on oral antidiabetic drugs: the openlabel, randomized GALAPAGOS study. J Diabetes Complic. 2015;29:838-45.

71. Garber AJ, Wahlen J, Wahl T, et al. Attainment of glycaemic goals in type 2 diabetes with once-, twice-, or thrice-daily dosing with biphasic insulin 
aspart 70/30 (The 1-2-3 study). Diabetes Obes Metab. 2006;8:58-66.

72. Vora J, Cohen $\mathrm{N}$, Evans $\mathrm{M}$, et al. Intensifying insulin regimen after basal insulin optimization in adults with type 2 diabetes: a 24-week, randomized, open-label trial comparing insulin glargine plus insulin glulisine with biphasic insulin aspart (LanScape). Diabetes Obes Metab. 2015;17: 1133-41.
73. Riddle MC, Rosenstock J, Gerich J. The treat-totarget trial: randomized addition of glargine or human NPH insulin to oral therapy of type 2 diabetic patients. Diabetes Care. 2003;26:3080-6.

74. Tinahones FJ, Gross JL, Onaca A, et al. Insulin lispro low mixture twice daily versus basal insulin glargine once daily and prandial insulin lispro once daily in patients with type 2 diabetes requiring insulin intensification: a randomized phase IV trial. Diabetes Obes Metab. 2014;16:963-70. 